\title{
Article
}

\section{A Widely Tunable Three-Section DBR Lasers for Multi-Species Gas Detection}

\author{
Hongyan Yu 1,2,3,*, Jiaoqing Pan ${ }^{1,2,3, * \mathbb{D}}$, Xuliang Zhou ${ }^{1,2,3}$, Hui Wang ${ }^{2,4}$, Liang Xie $2,4\left(\mathbb{D}\right.$ and Wei Wang ${ }^{1,2,3}$ \\ 1 Key Laboratory of Semiconductor Materials Science, Institute of Semiconductors, \\ Chinese Academy of Science, Beijing 100083, China; zhouxl@semi.ac.cn (X.Z.); wwang@semi.ac.cn (W.W.) \\ 2 College of Materials Science and Opto-Electronic Technology, University of Chinese Academy of Sciences, \\ Beijing 100049, China; whui@semi.ac.cn (H.W.); xiel@semi.ac.cn (L.X.) \\ 3 Beijing Key Laboratory of Low-Dimensional Semiconductor Materials and Devices, Beijing 100083, China \\ 4 State Key Laboratory on Integrated Optoelectronics, Institute of Semiconductors, \\ Chinese Academy of Sciences, Beijing 100083, China \\ * Correspondence: hyyu09@semi.ac.cn (H.Y.); jqpan@semi.ac.cn (J.P.); Tel.: +86-010-82304329 (J.P.)
}

Citation: Yu, H.; Pan, J.; Zhou, X.; Wang, H.; Xie, L.; Wang, W. A Widely Tunable Three-Section DBR Lasers for Multi-Species Gas Detection. Appl. Sci. 2021, 11, 2618. https://doi.org/ 10.3390/app11062618

Academic Editor: Matt Oehlschlaeger

Received: 20 January 2021

Accepted: 11 March 2021

Published: 15 March 2021

Publisher's Note: MDPI stays neutral with regard to jurisdictional claims in published maps and institutional affiliations.

Copyright: (c) 2021 by the authors. Licensee MDPI, Basel, Switzerland. This article is an open access article distributed under the terms and conditions of the Creative Commons Attribution (CC BY) license (https:/ creativecommons.org/licenses/by/ $4.0 /$ )

\begin{abstract}
We demonstrate a widely tunable distributed Bragg reflector (DBR) laser operating at $1.8-\mu \mathrm{m}$, in which the DBR section was butt-jointed $\operatorname{InGaAsP}(\lambda=1.45 \mu \mathrm{m})$ material. Through current and temperature tuning, a widely tuning range of over $11 \mathrm{~nm}$ with a side mode suppression ratio (SMSR) higher than $30 \mathrm{~dB}$ is obtained. Utilizing this DBR laser, the water and methane detection experiment has been successfully implemented, which illustrates the potential capacity of such DBR laser as the light source used for multispecies gas sensing. The work also illustrates that the butt-joint active-passive integration technology developed for the InGaAsP quantum-wells (QWs) can be successfully applied in the InGaAs QWs.
\end{abstract}

Keywords: butt-jointed; DBR laser; multispecies gas sensing

\section{Introduction}

In recent years, multi-gas detection has important applications in many fields such as production process optimization, medical health and environmental protection [1-3]. Due to its reliable, rapid, non-contact features, and low spectral interference, tunable diode laser absorption spectroscopy (TDLAS) is very promising in many different techniques [4-6]. A highly precise TDLAS gas sensing system requires its laser source possessing several special properties such as single-longitudinal-mode (SLM) and continuous wave (CW) operation, continuous tuning, mode-hop-free, and narrow spectral linewidth. TDLAS system commonly use distributed feedback (DFB) lasers as the light sources because of its simple fabrication process and narrow linewidth. Since the tuning range of DFB lasers is relatively small (one or two nanometers), it need multiple lasers in the multiple gases sensing system [7], which make the system very complex. In application, cost-effective monitoring, rapid measurement and equipment miniaturization is of great importance for an excellent gas sensing system, thus the widely tunable semiconductor lasers show their advantages when they are applied in such system $[8,9]$. At present, because of the rapid development of communications, the DBR lasers emitting at 1.5 and $1.3 \mu \mathrm{m}$ have been reported [10-14]. Furthermore, an arrayed waveguide based tunable quantum-dot (QD) laser with a ring structure, operating at around 1.6-1.8 $\mu \mathrm{m}$ has been developed by Tilma et al. fe tomography systems [15-18]. However, the 1.6-1.9 $\mu \mathrm{m}$ monolithic quantum-well DBR lasers have yet to be explored. The spectral range $(1.6$ to $1.9 \mu \mathrm{m})$ is consistent with the absorption spectrum of many gas species in environmental and industrial interest [19], such as water $\left(\mathrm{H}_{2} \mathrm{O}\right)$, methane $\left(\mathrm{CH}_{4}\right)$, nitric oxide $(\mathrm{NO})$, carbonic oxide $(\mathrm{CO})$, hydrogen chloride ( $\mathrm{HCL})$, carbon dioxide $\left(\mathrm{CO}_{2}\right)$, et al. So, this near-infrared wavelength range is important for spectroscopic and gas sensing applications. Although the 1.6-1.9 $\mu \mathrm{m}$ wavelength band is in the overtone and combination absorption region whose absorption features is much weaker 
than that of the fundamental absorption region $(2-20 \mu \mathrm{m})$, however, it is completely enough to achieve a sub ppm detection accuracy based on the TDLAS detection schemes [20]. It can be seen from the above, a widely tunable DBR laser is an ideal light source in the multiple gas detection applications.

By simulation, the photoluminescence (PL) wavelength of the grating material is proportional to the wavelength tuning range of the laser [21]. In order to get a larger tuning range, the InGaAsP bulk materials with a PL wavelength of $1.45 \mu \mathrm{m}$ which has the big refractive index difference under a fixed injection current are adopted as the butt-joint material in DBR section. Through the design, we get a total tuning range of $11 \mathrm{~nm}$. The lasing spectra can cover the absorption lines of multiple gases, $\left(\mathrm{HCL}, \mathrm{H}_{2} \mathrm{O}, \mathrm{N}_{2} \mathrm{O}, \mathrm{NO}, \mathrm{CH}_{4}\right.$ ) which are extracted from the HITRAN (high-resolution transmission molecular absorption) database, as shown in Figure 1. Sensing of those gases is attractive in environmental and industrial applications. Furthermore, we also study its application for measuring two spectral features of molecular gases (water and methane). It demonstrates that the DBR lasers we fabricate are capable of accurate wavelength scanning and are applicable for gas sensor. To our knowledge, this is the first demonstration of $1.8 \mu \mathrm{m}$ wavelength monolithic tunable DBR quantum-well laser diode for multispecies gas detection.

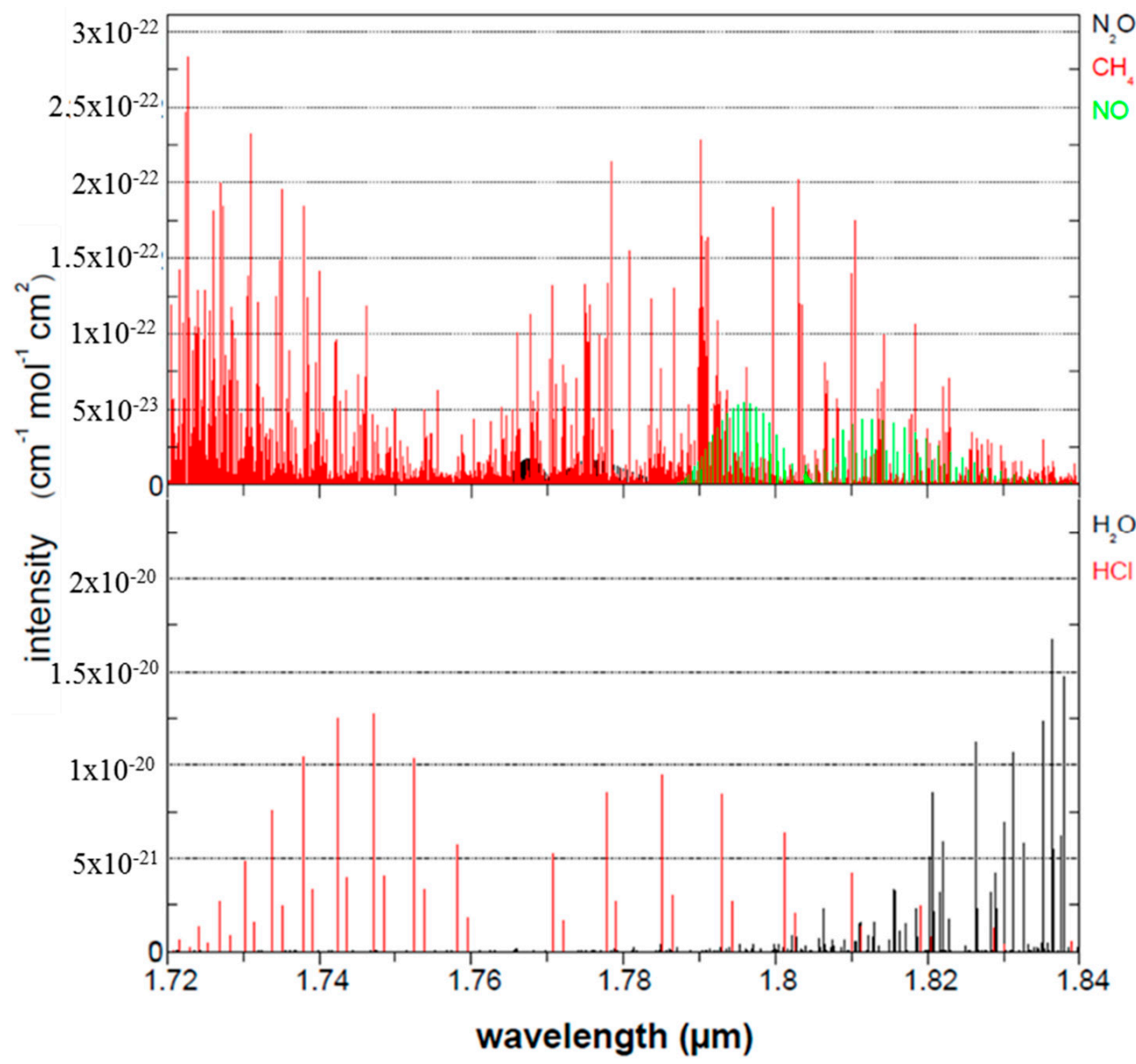

Figure 1. Absorption spectrums of different gas species in the 1720-1840 nm wavelength range which are extracted from the HITRAN (high-resolution transmission molecular absorption) 2016 database.

\section{Experimental Details}

Figure 2a shows the DBR laser's photograph. It is composed of three segments. The epitaxial layers of the device were grown on an n-InP substrate by the low pressure metalorganic chemical vapor deposition (MOCVD) with a three-step procedure. The active region composed of four $1.2 \%$ compressive strained $7-\mathrm{nm}$ InGaAs quantum wells and five 
$0.25 \%$ tensile strained $12-\mathrm{nm}$ InGaAsP barriers embedded in the separate confinement heterostructure ( $\mathrm{SCH}$ ) was grown in the first step, exhibiting a $1.78 \mu \mathrm{m}$ photoluminescence (PL) peak at room temperature (RT). After the first epitaxy, a 150-nm $\mathrm{SiO}_{2}$ layer was deposited as the mask, the active layers in the phase and DBR sections were removed selectively by wet chemical etchings. We usually use the selective 311 etchant $\left(\mathrm{H}_{2} \mathrm{SO}_{4}: \mathrm{H}_{2} \mathrm{O}_{2}: \mathrm{H}_{2} \mathrm{O}=3: 1: 1\right)$ to etch InGaAsP material, but the etching rate of 311 solutions is too fast for InGaAs materials. There is almost no report on the wet etching scheme of butt-joint integrated of InGaAs quantum-wells. According to the article [22], the less phosphors composition in InGaAsP, the faster the etch rate. After experimental exploration, we adopted optimized solutions $\left(\mathrm{H}_{2} \mathrm{SO}_{4}: \mathrm{H}_{2} \mathrm{O}_{2}: \mathrm{H}_{2} \mathrm{O}=2: 1: 5\right)$ which can avoid severe undercut at the interface of the passive and active regions. In the second growth step, the 340-nm InGaAsP (PL peak at $1.45 \mu \mathrm{m}$ ) waveguide layer was butt-jointed with the MQWs (multiple-quantum wells) layers in the gain section. Figure $2 b$ shows the SEM image of the butt-joint interface with no voids. The good butt-joint morphology is a key factor to device performance. Figure $2 \mathrm{c}$ shows the comparison of PL spectrum from the gain and passive waveguide section. The effective index change in the grating material strongly affects the tuning range [21]. A longer wavelength (smaller bandgap) of butt-joint grating material results in a larger index change in a fixed carrier injection, thus yielding a larger tuning range. Here, we used a $1.45-\mu \mathrm{m}$ InGaAsP (1.45Q) as the butt-joint layer which has a $340 \mathrm{~nm}$ wavelength detuning compared to the wavelength at the gain section $\left(\lambda_{\mathrm{g}}=1.78 \mu \mathrm{m}\right)$, ensuring both a sufficient low absorption loss and a large tuning range.

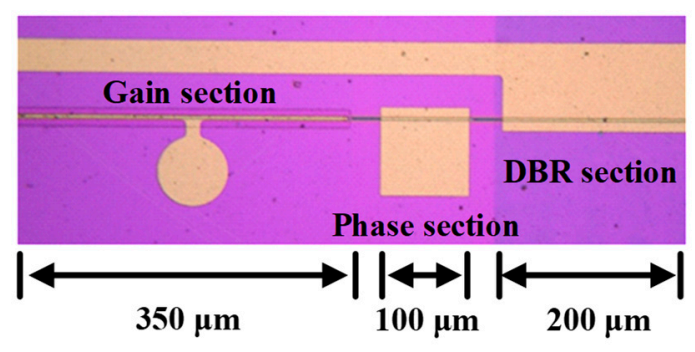

(a)

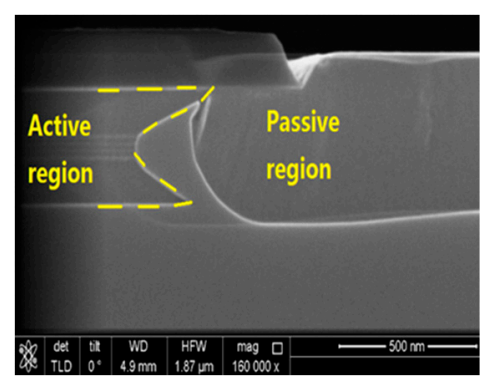

(b)

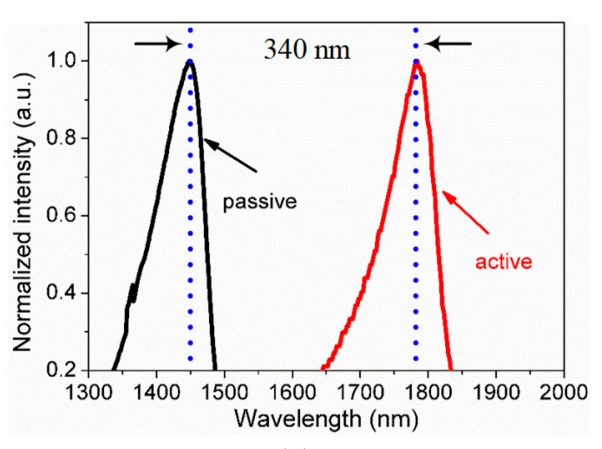

(c)

Figure 2. (a) Optical microscope image of the DBR (distributed Bragg reflector) laser. (b) Scanning electron microscope (SEM) image of the butt-joint interface. (c) Photoluminescence (PL) spectra of the butt-joint material and the active material [23].

After waveguide layer and the MQWs were butt-jointed by the MOCVD epitaxial growth, grating corrugations were fabricated in the $1.45 \mathrm{Q}$ of the DBR section using conventional holographic lithography and reactive ion etching (RIE), respectively. Afterwards, a p-InP cladding layer and a p+-InGaAs contact layer were implemented in the third step regrowth. When the whole layer structure was finished, a ridge waveguide with the width of $3 \mu \mathrm{m}$ was formed by photolithography and wet chemical etching. Then, a 50- $\mu \mathrm{m}$ isolation gap between the three sections (DBR section, phase section, and gain section) was accomplished by moving the $\mathrm{p}+-\mathrm{InGaAs}$ contact layer away. The following $\mathrm{He}^{+} \mathrm{im}$ plantation was implemented to these gaps to increase the electrical insulation. To provide the lateral current confinement, a $\mathrm{SiO}_{2}$ insulating layer was deposited with a 3- $\mu \mathrm{m}$-width current injection window opened above the ridge waveguide. A Ti-Au metal layer was used for a P-contact metallization. AuGeNi/Au was evaporated on the bottom side of the wafer after thinning the substrate. The chips composed of a 350- $\mu \mathrm{m}$ gain section, a $100-\mu \mathrm{m}$ phase section and a 200- $\mu \mathrm{m}$ DBR section were cleaved with both sides uncoated (Figure 2a). 


\section{Results and Discussion}

\subsection{Characterization of the DBR Laser}

First, the electro-optical characteristics of the device are measured at different temperature, as shown in Figure 3a, with a current of the DBR and phase section $0 \mathrm{~mA}$. The optical power is measured from the gain section facet of the device by an integrating sphere. We can see that, with the temperature increasing from 15 to $35^{\circ} \mathrm{C}$, the threshold current of the device increases (20 to $30 \mathrm{~mA}$ ) and the laser power decreases (9.9 to $6.9 \mathrm{~mW})$. The data are analyzed in the empirical relation, $I t h=I_{0} \exp \left(T / T_{0}\right)$, the characteristic temperature $T_{0}$ is determined to be $53 \mathrm{~K}$. The value of $T_{0}$ obtained here is comparable to the conventional $1.65-\mu \mathrm{m}$ DFB lasers. The laser's emission wavelength redshifts with the temperature. The temperature-tuning rate is $0.11 \mathrm{~nm} /{ }^{\circ} \mathrm{C}$ when the gain current is maintained at $60 \mathrm{~mA}$, as shown in Figure $3 \mathrm{~b}$. This indicates that in addition to the tuning of DBR and phase currents, the tuning range of the DBR laser can also be expanded effectively by changing the temperature. Meanwhile the SMSR properties of the device are not deteriorated.

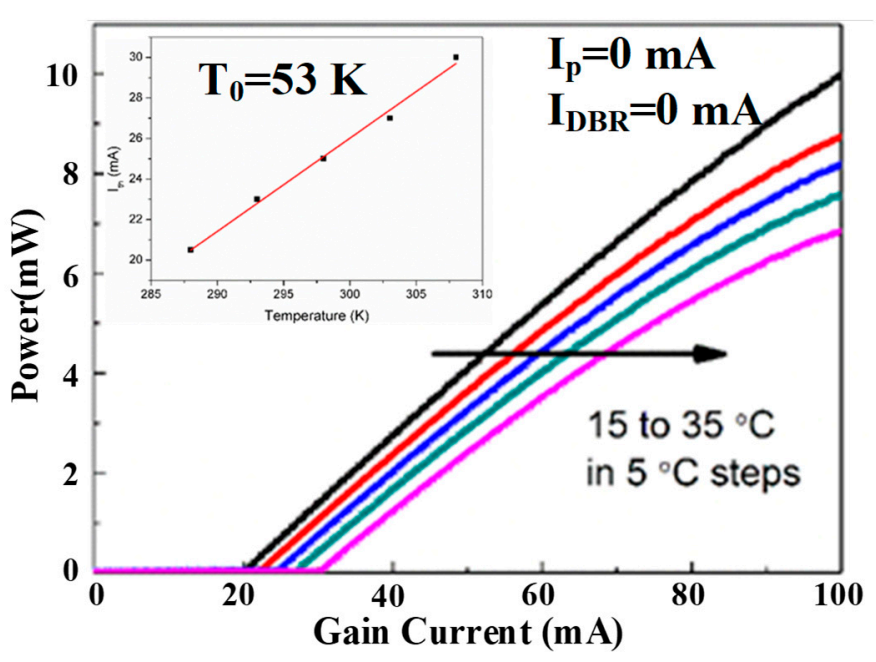

(a)

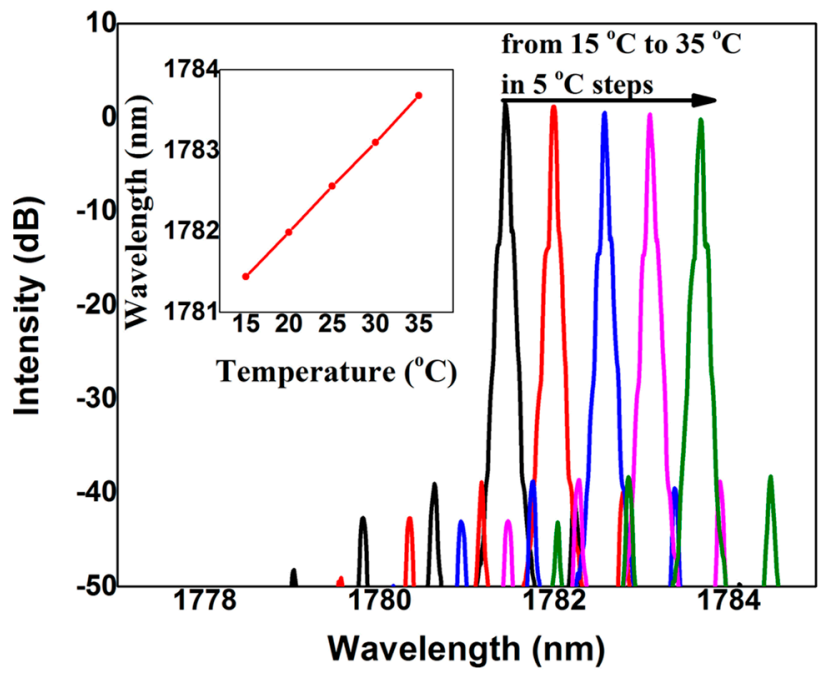

(b)

Figure 3. (a) CW (continuous wave) L-I (Light-Current) characteristics of the DBR laser at the temperatures between 15 to $35^{\circ} \mathrm{C}$. Inset shows the threshold current dependence on mount temperature. (b) Lasing spectrum of the DBR laser at different temperature at $60 \mathrm{~mA}$ gain current.

Then, the wavelength tuning character is investigate by varying the phase and DBR current. The lasing wavelength dependence on the DBR current at $25^{\circ} \mathrm{C}$ in a fixed gain current of $60 \mathrm{~mA}$ is shown in Figure 4a. It can be seen from the figure, the lasing wavelength can be switched digitally over 11 consecutive channels for about a tuning range of $9 \mathrm{~nm}$, when increasing the DBR current from 0 to $100 \mathrm{~mA}$. The channel wavelength blue shifts when the DBR current increasing. From the tuning characteristics of DBR section, it indicates that the tuning physical mechanism is determined by the free-carrier (FC) injection effect. However, a tuning saturation takes place when the DBR current is increased to $63 \mathrm{~mA}$. Actually, the tuning saturation which is caused by the self-heating effect can be improved by designing and selecting the coupling coefficient $k$ and the length of Bragg grating carefully. The longer the PL wavelength of the grating material, the bigger effective refractive index change at the same density of the injected FC [21]. So, we can get a larger tuning range by selecting a narrower bandgap DBR material. 


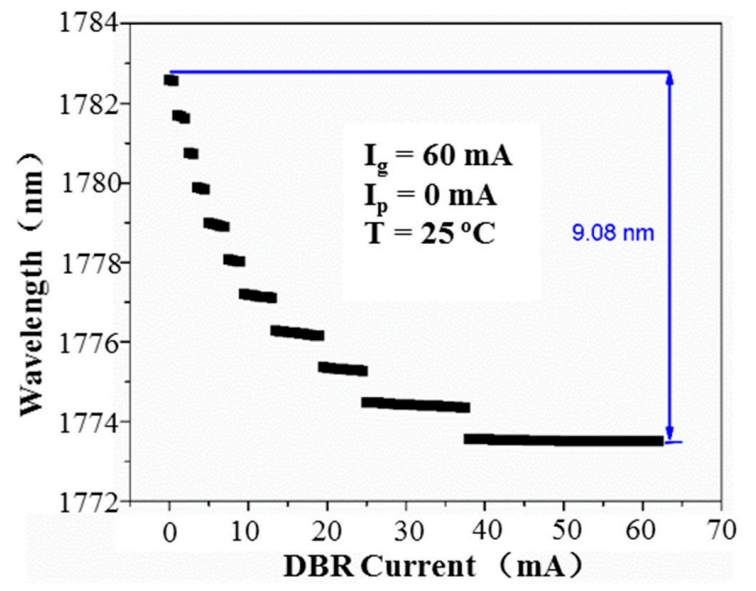

(a)

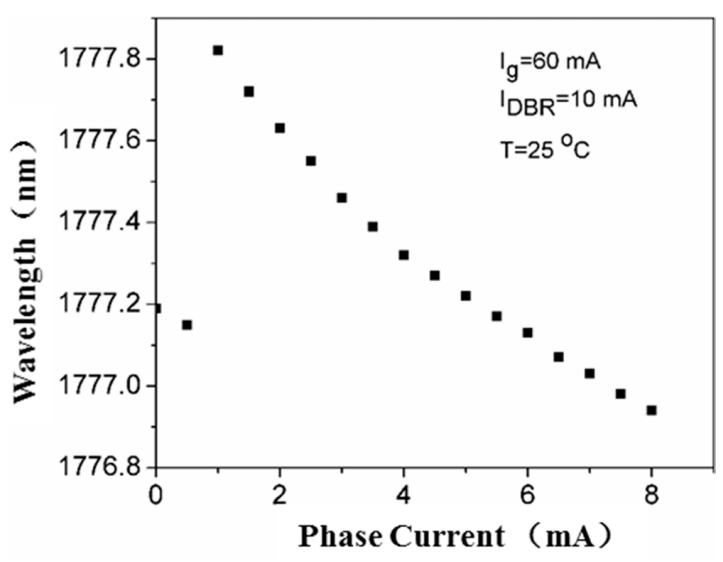

(b)

Figure 4. (a) Lasing wavelength dependence on DBR current. (b) Lasing wavelength dependence on Phase current [23].

By changing the current in the DBR section, the lasing wavelength of the laser can be tuned continuously in the separate channel and it is not continuous between channels. This can be compensated by tuning the phase current. Through the phase current adjusting, the wavelength shift can cover the gaps between two channels where the mode hopping happens, which is shown in Figure $4 \mathrm{~b}$. The emission wavelength sweeps $0.88 \mathrm{~nm}$ continuously as the phase current increasing from 1 to $8 \mathrm{~mA}$. The single channel range realized by the phase current is larger than the 0.8 -nm mode-spacing. Therefore, a continuous tuning range can be realized by combining injected current of DBR and phase area.

Combined with the temperature tuning (increasing the heat sink temperature from 15 to $35^{\circ} \mathrm{C}$ ), the tuning range of the device can be further increased from 9 to $11 \mathrm{~nm}$, as shown in Figure 5a. For gas detection, the side mode suppression ratio (SMSR) is also a key parameter to DBR lasers. The SMSR of higher than $30 \mathrm{~dB}$ are obtained for all channels, as shown in Figure 5b.

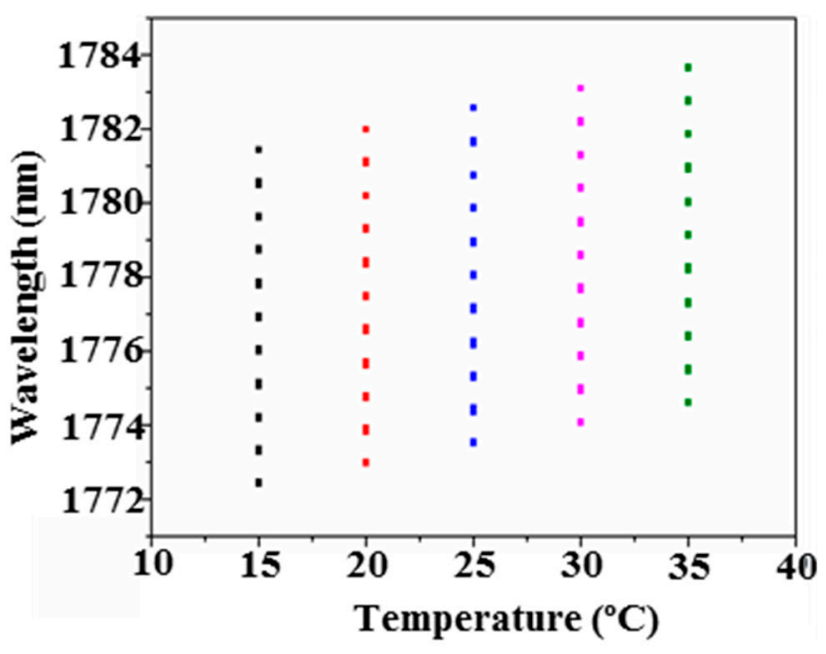

(a)

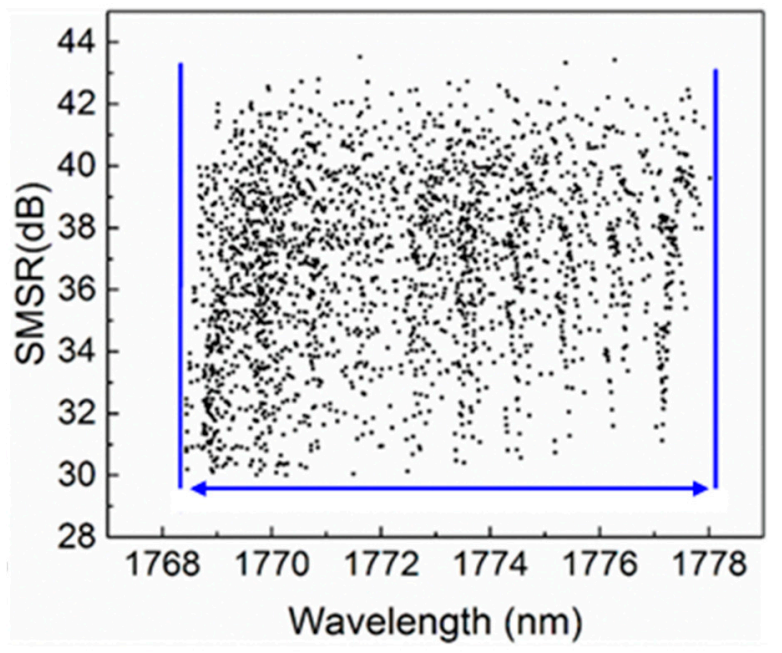

(b)

Figure 5. (a) Lasing wavelength varies with DBR current and work temperature. (b) The SMSR (side mode suppression ratio) of DBR laser over the entire wavelength range [23].

In practical applications, the beam quality of the laser is also an aspect that needs to be considered. Generally, the far-field characteristics can be used as a parameter to evaluate the quality of the laser beam. We measured the far-field characteristics of the DBR 
laser in a $60 \mathrm{~mA}$ gain current at room temperature. The horizontal and vertical divergence angles are $14^{\circ}$ and $36^{\circ}$, respectively, which is comparable with the traditional DFB lasers for communication. Furthermore, we also tested the device's wavelength stability for seven hours when the temperature of the laser was controlled to $20^{\circ} \mathrm{C}$, as shown in Figure 6. It can be seen from the figure that the wavelength change of the laser is less than $0.05 \mathrm{~nm}$ which is the minimum resolution of the spectrometer.

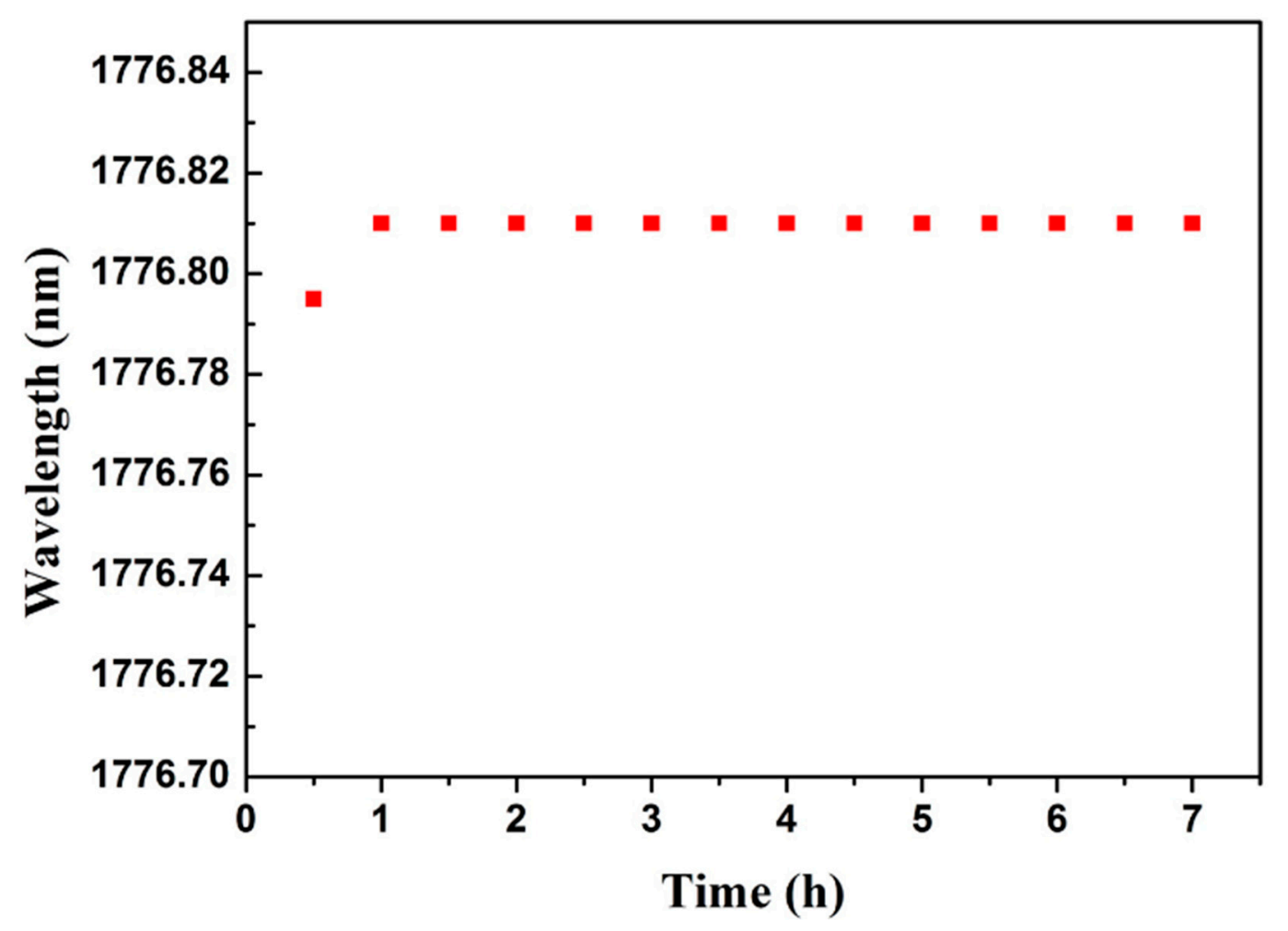

Figure 6. Lasing wavelength varies with work time.

It can be seen from the above test results that the DBR laser can achieve continuous wavelength tuning, single-mode output, and good wavelength stability, which meet the requirements of light source for gas detection.

\subsection{Experimental Setup of TDLAS}

To demonstrate the DBR laser's possibilities in multi-gas detection, the experimental setup of the gas detection system based on TDLAS technology is schematically illustrated in Figure 7. For the convenience of gas sensing, an industry standard 14-pin butterfly packaging scheme of the DBR laser chip is adopted and the whole device is integrated with thermistor, thermo-electric cooler (TEC), optical isolator, and the photo-detector (PD).

Temperature control circuit ensures the DBR laser working at a proper temperature, stabilizing the output power, and locking laser emission peak to the absorption line of the target gas. The laser is modulated by two waveform generators. One is to generate a low frequency triangular wave providing a slow wavelength scan by a function generator. The other is to superimpose a high frequency sinusoidal modulation to the laser by a lock-in amplifier. The modulated light is guided to the gas cell which is filled with target gas and is detected by a photo-detector (PD) which transforms the optical signals to the electrical ones. Finally, the electrical signals are sent to another lock-in amplifier where such signals are demodulated, outputting the signals in a second harmonic type. 


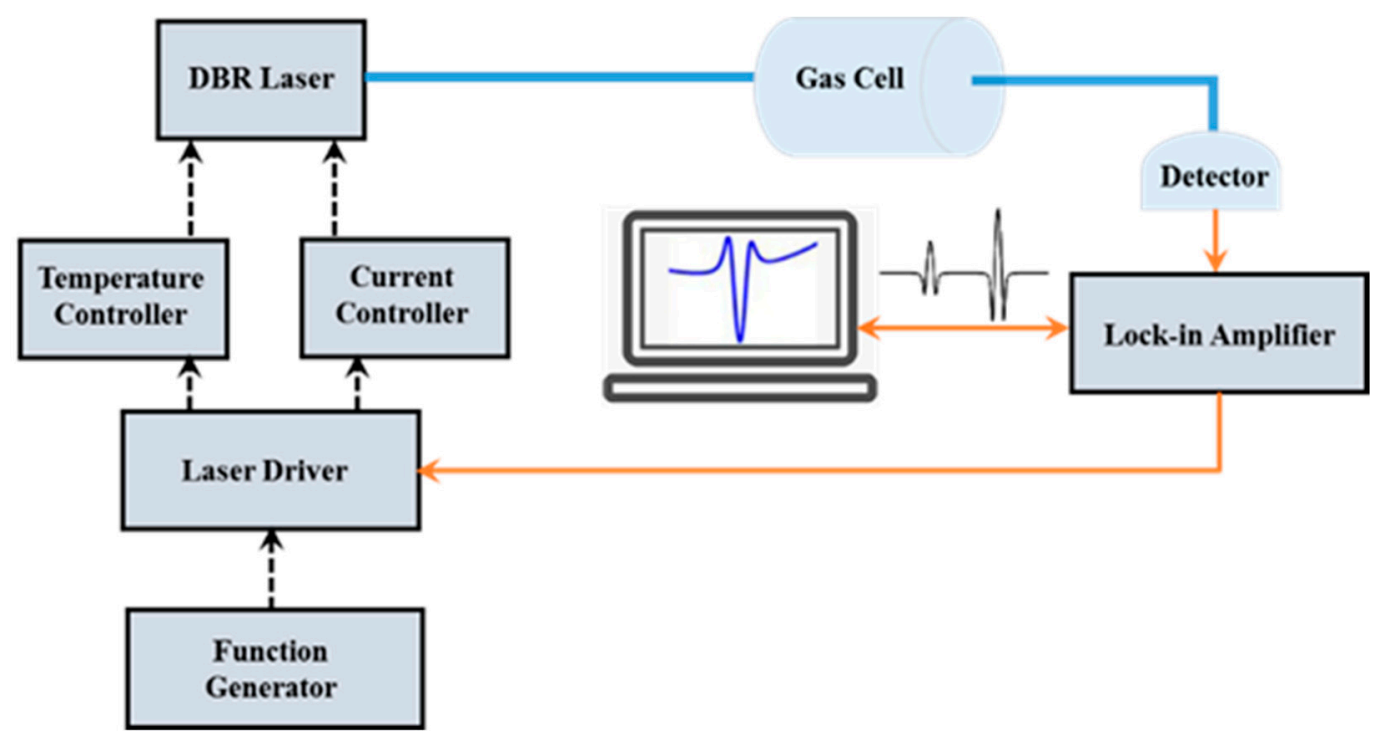

Figure 7. TDLAS (tunable diode laser absorption spectroscopy) experimental setup for the gas detection.

According to the spectra extracted from Hitran database, we choose absorption lines around $1781 \mathrm{~nm}$ which corresponds to that of methane and water for detection experiment, as shown in Figure 8. The peak emission wavelength of the DBR laser is $1781 \mathrm{~nm}$ with a SMSR of $40 \mathrm{~dB}$ when the gain current is $75 \mathrm{~mA}$ at $22{ }^{\circ} \mathrm{C}$. For $\mathrm{H}_{2} \mathrm{O}$ detection, a $1 \mathrm{kHz}$ triangular ramp (gain current varied from 62 to $86 \mathrm{~mA}$ ) and a $10 \mathrm{kHz}$ sinusoidal modulation (with the amplitude of $6.48 \mathrm{~mA}$ ) are applied to the driving current in the gain section while the current in the DBR section is set to $0 \mathrm{~mA}$. For methane detection, the applied signal in the gain section is the same with $\mathrm{H}_{2} \mathrm{O}$ applied except an additional $4 \mathrm{~mA}$ current in the DBR section.

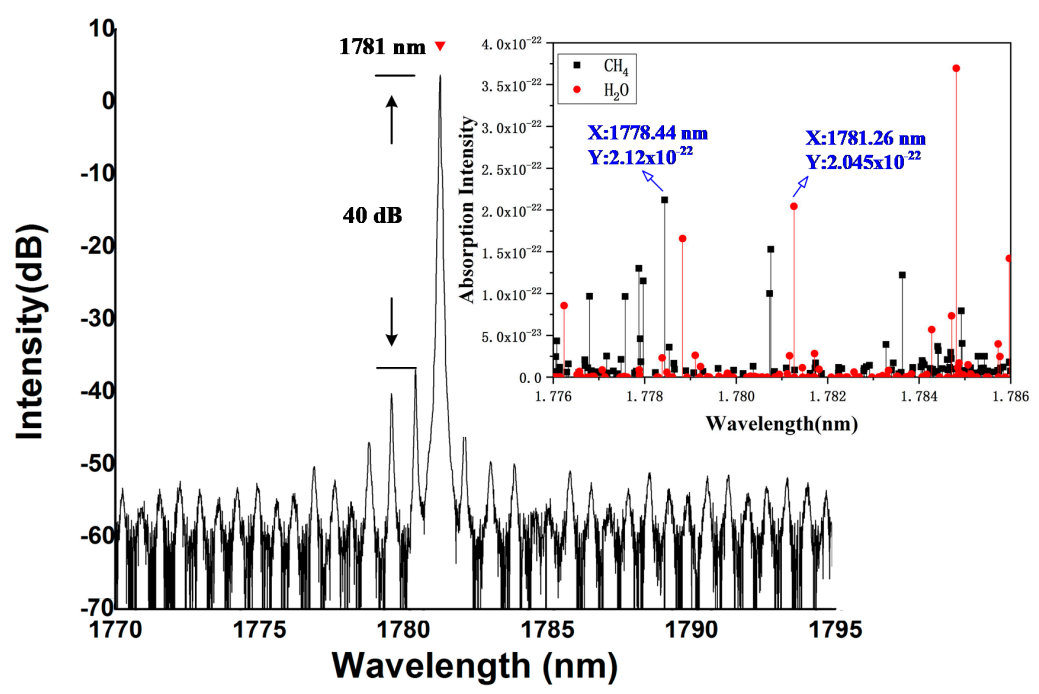

Figure 8. The spectrum of DBR laser near the absorption lines of the measured gas. Inset is the selected absorption lines of methane and water in the gas detection experiment.

The second harmonic curve (the " $2 \mathrm{f}$ " curve) of $\mathrm{H}_{2} \mathrm{O}$ and $\mathrm{CH}_{4}$ is shown in Figure 9. The

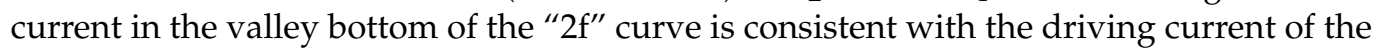
DBR laser in which the emitting wavelength corresponding to the sample gas absorption line. In other words, the " $2 \mathrm{f}$ " curve contains a dip where the sample gas absorbed at the wavelength corresponding to that laser current. The current at the dip represents the driving current of the laser at the wavelength of interest. 


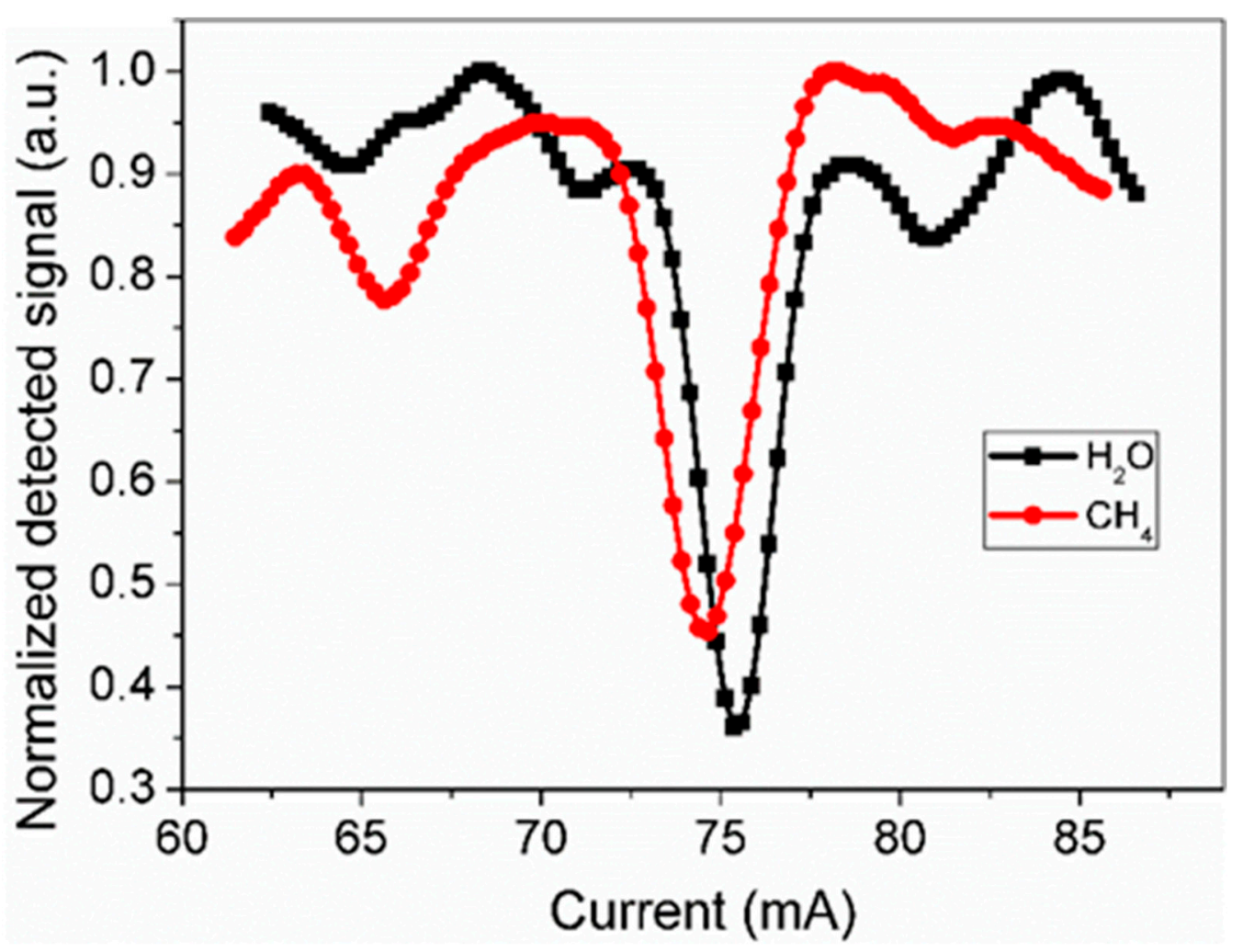

Figure 9. The second harmonic curve extracted from the lock-in amplifier (water-black, methane-red) [23].

The theoretical formula of TDLAS is based on the Beer-Lambert law. For a single frequency laser, the light intensity changes can be described as follows [24]:

$$
I(v)=s I_{0}(v) \exp [-\alpha(v) C L]
$$

where $s$ is the light collection efficiency, which is the ratio of laser power received by the photo-detector to the original optical power without gas absorption; $I(v)$ and $I_{0}(v)$ are the transmitted and incident laser intensities, respectively; $\alpha(v)$ is the spectral absorption coefficient in unit length and unit concentration at the frequency of $v ; C$ is the concentration of sample gas; $L$ is the length of optical path. The working principle is that, when a light beam at a specific wavelength which is modulated passes through the target gas at a path length $L$ and the transmitted laser power is measured by a PD. The amount of light intensity lost (absorbed by the sample gas) is proportional to the gas concentration in the path of light. Analyzing this second harmonic data extracted from the lock-in amplifier, the gas concentration value can be calculated.

\section{Conclusions}

Through butt-joint growth technology, a three-section InGaAs/InGaAsP DBR laser has been fabricated. The DBR section was realized by using butt-jointed InGaAsP $\left(\lambda_{\mathrm{PL}}=1.45 \mu \mathrm{m}\right)$ material. A total tuning range of $11 \mathrm{~nm}$ with a SMSR higher than $30 \mathrm{~dB}$ is obtained. Simultaneous detection of methane and water vapor experiments are implemented, which shows that such DBR lasers possess significant advantages for multiple gas species detection.

Author Contributions: Conceptualization, J.P., L.X., X.Z.; methodology, H.Y., H.W., X.Z.; formal analysis, H.Y.; investigation, H.Y.; writing-original draft preparation, H.Y.; writing-review and editing, H.Y., J.P.; visualization, H.Y.; supervision, J.P., L.X., W.W.; project administration, J.P.; funding acquisition, J.P. All authors have read and agreed to the published version of the manuscript. 
Funding: The work was supported by the National Key Research and Development Program of China (2017YFB0405301), Beijing Municipal Science and Technology Project (Z191100004819011), Frontier Science Research Project of CAS (Chinese Academy of Science) (QYZDY-SSW-JSC021), National Key Research and Development Program of China (2018YFA0209001).

Institutional Review Board Statement: Not applicable.

Informed Consent Statement: Not applicable.

Data Availability Statement: Not applicable.

Acknowledgments: The authors thank Zhibo Li for useful discussions. Portions of this work were presented at the Asia Communications and Photonics (ACP) Conference in 2017, published by Optical Society of America (OSA), Su2B.6 [22].

Conflicts of Interest: The authors declare no conflict of interest.

\section{References}

1. Bakhirkin, Y.A.; Kosterev, A.A.; Roller, C.; Curl, R.F.; Tittel, F.K. Mid-infrared quantum cascade laser based off-axis integrated cavity output spectroscopy for biogenic nitric oxide detection. Appl. Opt. 2004, 43, 2257-2266. [CrossRef]

2. Kluczynski, P.; Lundqvist, S.; Belahsene, S.; Rouillard, Y.; Nahle, L.; Fischer, M.; Koeth, J. Detection of propane using tunable diode laser spectroscopy at $3.37 \mu \mathrm{m}$. Appl. Phys. A 2012, 108, 183-188. [CrossRef]

3. Nadezhdinskii, A.; Ponurovskii, Y.; Stavrovskii, D. Non-contact detection of explosives by means of a tunable diode laser spectroscopy. Appl. Phys. A 2008, 90, 361-364. [CrossRef]

4. Yang, B.; He, G.-Q.; Liu, P.-J.; Qi, Z.-M. Design of Diode Laser Sensor Based on TDLAS for Rocket Based Combined Cycle. Symp. Photonics Optoelectron. 2011, 1-4. [CrossRef]

5. Durry, G.; Li, J.S.; Vinogradov, I.; Titov, A.N.; Joly, L.; Cousin, J.; Decarpenterie, T.; Amarouche, N.; Liu, X.; Parvitte, B.; et al. Near infrared diode laser spectroscopy of $\mathrm{C} 2 \mathrm{H} 2, \mathrm{H} 2 \mathrm{O}, \mathrm{CO} 2$ and their isotopologues and the application to TDLAS, a tunable diode laser spectrometer for the martian PHOBOS-GRUNT space mission. Appl. Phys. A 2010, 99, 339-351. [CrossRef]

6. Sigrist, M.; Bartlome, R.; Marinov, D.; Rey, J.; Vogler, D.; Wachter, H. Trace gas monitoring with infrared laser-based detection schemes. Appl. Phys. A 2008, 90, 289-300. [CrossRef]

7. Besson, J.-P.; Schilt, S.; Thévenaz, L. Multi-gas sensing based on photoacoustic spectroscopy using tunable laser diodes. Spectrochim. Acta Part A Mol. Biomol. Spectrosc. 2004, 60, 3449-3456. [CrossRef]

8. Phelan, R.; Lynch, M.; Donegan, J.F.; Weldon, V. Simultaneous multispecies gas sensing by use of a sampled grating distributed Bragg reflector and modulated grating Y laser diode. Appl. Opt. 2005, 44, 5824-5831. [CrossRef]

9. Shao, J.; Han, Y.; Guo, J.; Wang, L.; Han, Y.; Zhou, Z.; Kan, R. Multigas detection using a sample-grating distributed Bragg reflector diode laser. Appl. Opt. 2013, 52, 7462-7468. [CrossRef]

10. Kan, Q.; Ding, Y.; Zhao, L.; Zhu, H.; Zhou, F.; Wang, L.; Wang, B.; Wang, W. Offset Quantum-Well Method for Tunable Distributed Bragg Reflector Lasers and Electro-Absorption Modulated Distributed Feedback Lasers. Chin. Opt. Lett. $2005,3,455-456$.

11. Shinoda, K.; Kitatani, T.; Aoki, M.; Mukaikubo, M.; Uchida, K.; Uomi, K. 1.3- $\mu$ m InGaAlAs Short-Cavity DBR Lasers for Uncooled 10-Gb/s Operation With Low Drive Current. IEEE Photon Technol. Lett. 2006, 18, 2383-2385. [CrossRef]

12. Afzal, S.; Scholz, W.; Gready, D.; Eisenstein, G.; Melanen, P.; Vilokkinen, V.; Vallone, M.; Schnabel, F.; Reithmaier, J.P.; Montrosset, I. 1.3- $\mu \mathrm{m}$ Two-Section DBR Lasers Based on Surface Defined Gratings for High-Speed Telecommunication. IEEE Photon Technol. Lett. 2011, 23, 411-413. [CrossRef]

13. Han, L.; Liang, S.; Xu, J.; Qiao, L.; Wang, H.; Zhao, L.; Zhu, H.; Wang, W. DBR Laser with over 20nm Wavelength Tuning Range. IEEE Photon Technol. Lett. 2016, 28, 1. [CrossRef]

14. Han, L.H.L.; Liang, S.L.S.; Zhang, C.Z.C.; Yu, L.Y.L.; Zhao, L.Z.L.; Zhu, H.Z.H.; Wang, B.W.B.; Ji, C.J.C.; Wang, W.W.W. Fabrication of widely tunable ridge waveguide DBR lasers for WDM-PON. Chin. Opt. Lett. 2014, 12, 091402-91405. [CrossRef]

15. Tilma, B.W.; Bente, E.A.J.M.; Leijtens, X.J.M.; Nötzel, R.M.; Smit, K. Design of an Integrated Electro-Optically Tuna-ble Filter for Tunable Laser Purposes. In Proceedings of the 14th European Conference on Integrated Optics (ECIO), Eindhoven, The Netherlands, 11-13 June 2008; pp. 181-184.

16. Tilma, B.W.; Tahvili, M.S.; Kotani, J.; Nötzel, R.; Smit, M.K.; Bente, E.A.J.M. Measurement and analysis of optical gain spectra in 1.6 to $1.8 \mu \mathrm{m}$ InAs/InP (100) quantum-dot amplifiers. Opt. Quantum Electron. 2009, 41, 735-749. [CrossRef]

17. Tilma, B.W.; Jiao, Y.; Van Veldhoven, P.J.; Smalbrugge, B.; Ambrosius, H.P.M.M.; Thijs, P.J.; Leijtens, X.J.M.; Nötzel, R.; Smit, M.K.; Bente, E.A.J.M. InP-Based Monolithically Integrated Tunable Wavelength Filters in the 1.6-1.8 $\mu$ m Wavelength Region for Tunable Laser Purposes. J. Light. Technol. 2011, 29, 2818-2830. [CrossRef]

18. Tilma, B.W.; Jiao, Y.Y.; Kotani, J.J.; Smalbrugge, E.B.; Ambrosius, H.P.M.M.; Thijs, P.P.; Leijtens, X.J.M.; Ntzel, R.; Smit, M.K.; Bente, E.A.J.M. Integrated Tunable Quantum-Dot Laser for Optical Coherence Tomography in the $1.7 \mu \mathrm{m}$ Wavelength Region. IEEE J. Quantum Electron. 2011, 48, 87-98. [CrossRef]

19. Zeller, W.; Naehle, L.; Fuchs, P.; Gerschuetz, F.; Hildebrandt, L.; Koeth, J. DFB Lasers Between $760 \mathrm{~nm}$ and 16 m for Sensing Applications. Sensors 2010, 10, 2492-2510. [CrossRef] 
20. O'Gorman, J.; Weldon, V.; McDonald, D.; Perez-Camacho, J.J.; Corbett, B.; Hegarty, J. Gas sensing using IR laser diode sources. In Proceedings of the Chemical, Biochemical and Environmental Fiber Sensors IX, Munich, Germany, 30 May 1997; Volume 3105, pp. 301-316. [CrossRef]

21. Weber, J.-P. Optimization of the carrier-induced effective index change in InGaAsP waveguides-application to tunable Bragg filters. IEEE J. Quantum Electron. 1994, 30, 1801-1816. [CrossRef]

22. Pasquariello, D.; Bjorlin, E.; Lasaosa, D.; Chiu, Y.-J.; Piprek, J.; Bowers, J. Selective undercut etching of InGaAs and InGaAsP quantum wells for improved performance of long-wavelength optoelectronic devices. J. Light. Technol. 2006, 24, 1470-1477. [CrossRef]

23. Yu, H.; Wang, P.; Mi, J.; Zhou, X.; Pan, J.; Wang, H.; Xie, L.; Wang, W. 1.8- $\mu$ m DBR Lasers with Over 11-nm Continous Wavelength Tuning Range for Multi-Species Gas Detection. In Proceedings of the 2017 Asia Communications and Photonics Conference (ACP), Guangzhou, China, 10-13 November 2017; pp. 8-10. [CrossRef]

24. Zhang, T.-T.; Wei, Y.-B.; Wang, C.; Liu, T.-Y. Research of optic fiber CO concentration monitoring virtual system based on TDLAS. In Proceedings of the International Symposium on Photoelectronic Detection and Imaging 2011, Beijing, China, 24-26 May 2011; Volume 8192, p. 81922. 